\title{
Community Pharmacist Views On The Early Stages Of Implementation Of A Pathfinder Sore Throat Test And Treat Service In Wales: An Exploratory Study
}

This article was published in the following Dove Press journal: Integrated Pharmacy Research and Practice

\author{
Efi Mantzourani $\mathbb{D}^{1,2}$ \\ Ricky Hicks' \\ Andrew Evans ${ }^{3}$ \\ Emma Williams $\mathbb{1 D}^{2}$ \\ Cheryl Way ${ }^{2}$ \\ Rhian Deslandes'
}

'School of Pharmacy and Pharmaceutical Sciences, Cardiff University, Cardiff, Wales, UK; ${ }^{2} \mathrm{NHS}$ Wales Informatics Service, Primary Care Services, Cardiff, Wales, UK; ${ }^{3}$ Welsh Government, Health and Social Services, Cardiff, Wales, UK

Correspondence: Efi Mantzourani NHS Wales Informatics Service,

Cowbridge Road, Cardiff, UK and School of Pharmacy and Pharmaceutical Sciences, Cardiff University, Redwood Building, King Edward VII Avenue, Cardiff CFIO 3NB, UK

Tel +442920870452

Email MantzouraniEI@cardiff.ac.uk
Objectives: To explore the views and opinions of community pharmacists regarding their initial experience of and levels of preparedness for the pathfinder sore throat test and treat (STTT) service in Wales.

Methods: A phenomenological qualitative approach with constructivist paradigm was adopted as the first cycle of ongoing action research. Semi-structured interviews with community pharmacists who had completed at least three consultations within the first 3 weeks of the service were conducted, with informed consent and audio recorded. Interviews were transcribed ad verbatim and data were thematically analysed both inductively and deductively.

Results: A total of seven interviews with pharmacists who had conducted more than three consultations identified three main themes: 1) perceived impact of the service on patient care, including the value of the structure and technology infrastructure, the role of STTT towards antimicrobial stewardship, and its potential role in rebalancing primary care resources so that workload is distributed appropriately among healthcare professionals; 2) factors that empower pharmacists to deliver the service, in particular quality and consistency of training, appropriate staffing resource and internally motivated willingness to engage; 3) interface with GP surgeries such as nature of existing relationships before implementing the service, role of GP staff and GP perceived value of STTT.

Conclusion: The pathfinder STTT service has been well received by pharmacists who recognised the service's role in providing patient education and contributing to principles of antimicrobial stewardship and described factors that would empower them to deliver the service confidently. Results have been fed back to the service implementation team to inform future developments.

Keywords: sore throat test and treat, point-of-care testing, community pharmacy, antimicrobial stewardship, pharmacy services

\section{Introduction}

Community pharmacists (CPs) are key members of the National Health Service (NHS) in the United Kingdom (UK) and have a fundamental role in improving patient care. Over recent years, the CP role within the UK has evolved significantly with greater emphasis on utilising their clinical skills, with an increasing number of advanced services being commissioned, moving towards fully integrated community-based provision of healthcare.

Pharmacists have traditionally advised patients on the symptomatic management of acute sore throat; however, their scope of practice is often limited and only symptomatic 
treatment with analgesics available over the counter has been possible. Additionally, patients often have a high expectation of receiving an antibiotic for sore throats and as a result, largely visit their General Practitioner (GP). ${ }^{1}$ Approximately 180,000 UK GP consultations are being utilised for sore throat management per year and, in 2016, 122,000 antibiotic prescriptions were dispensed for the treatment of acute sore throats, ${ }^{2}$ even though there is little evidence for their use. This overprescribing of antibiotics is a contributing factor to increased antimicrobial resistance (AMR), a worldwide threat that could become the leading cause of death by 2050 .

Pharmacists can play a crucial role in antimicrobial stewardship. In Wales, CPs have been able to provide analgesics for symptomatic treatment of acute sore throats free of charge to patients since 2013 through the Common Ailment Scheme (CAS), an NHS service covering twenty-six pre-defined conditions. ${ }^{3}$ No clinical examination was part of the scheme and the option of supplying antibiotics for sore throats was not included. A stratified approach of adding a Point-of-Care test (POCT) to a clinical examination in primary care settings has been suggested by $\mathrm{NICE}^{4}$ as helpful towards identifying individuals who are asymptomatic carriers of group A streptococcus (GAS) and reducing unnecessary antibiotic supplies, as a potential strategy to help tackle AMR. Throat swabs and POCT are not routinely part of a GP examination, due to associated delays in receiving bacteriology results from separate laboratories. In a recent review of POCT use, the authors concluded that the tests are suitable to conduct within community pharmacy ${ }^{5}$ and support the CPs in their decision-making process.

In an attempt to guide antibiotic supplies for sore throats, an NHS funded Sore Throat Test and Treat (STTT) service was introduced in community pharmacy pilot sites in November 2018, as an extension of Wales' CAS for sore throats. CPs who have received additional training and are working in participating pharmacies can consider supplying patients with antibiotics in line with a Patient Group Direction (PGD) if pre-defined clinical criteria are met (using FeverPAIN or CENTOR scoring tools) and a subsequent positive POCT is indicative of the presence of GAS. The pathfinder STTT service rolled out incrementally across two local Health Boards in Wales with 23 pharmacies in the first phase (November 2018) extending to 56 by the end of the pilot (June 2019). This pilot service was made available to adults and children over six years of age who could self-refer or be referred by another healthcare professional to a participating pharmacy for advice and treatment (Figure 1). ${ }^{6}$

A test and treat service was piloted by a large pharmacy chain in a small number of pharmacies in central

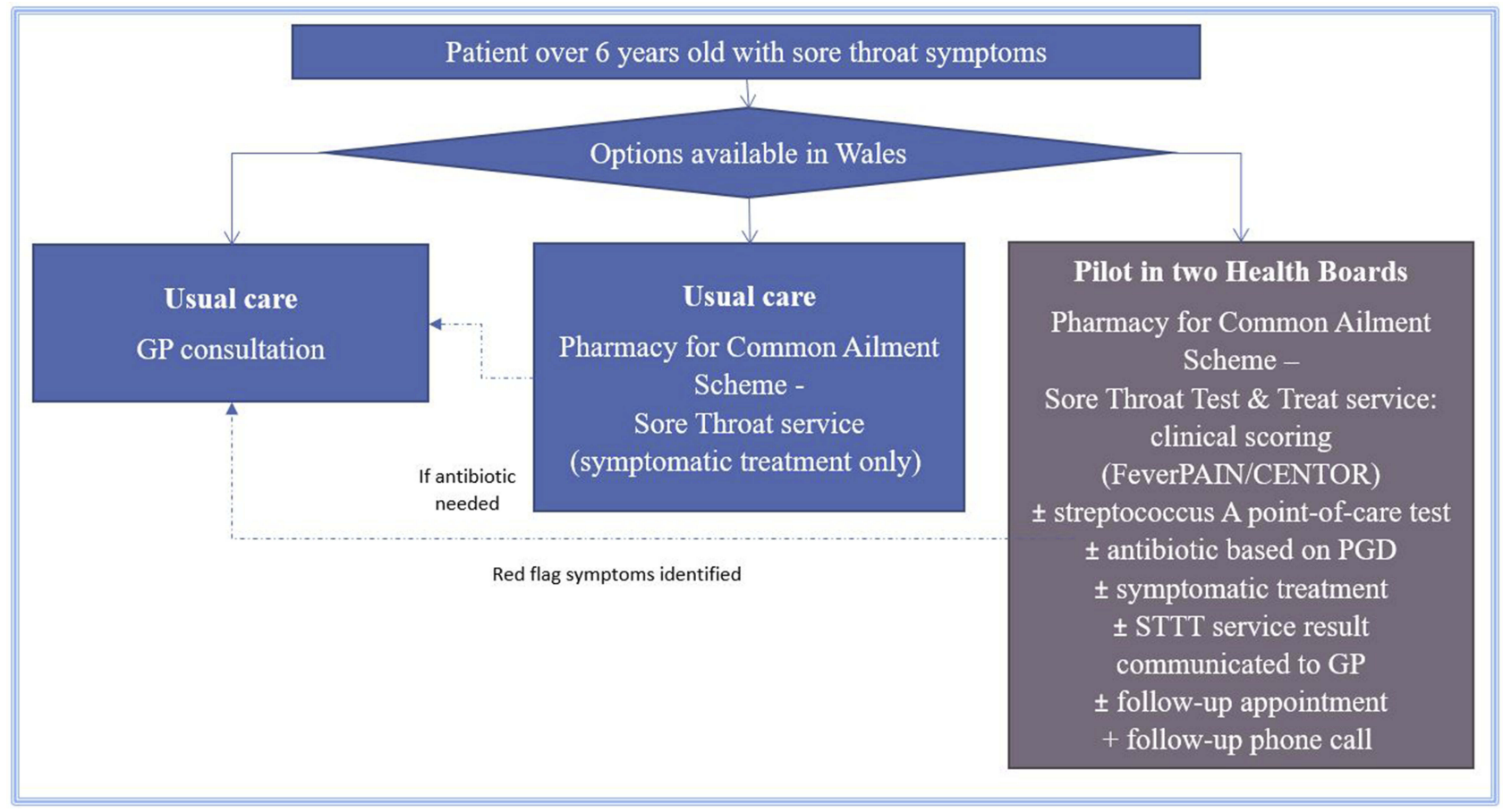

Figure I An overview of the Sore Throat Test and Treat (STTT) service and how it fits within the options available in Wales for patients over 6 years old with sore throat symptoms. 
London and Leicestershire; however, the service was not NHS commissioned. ${ }^{7}$ The clinical outcomes of the pilot service were evaluated, and it was concluded that the service could prevent unnecessary antibiotic use $^{7}$ and could reduce the number of patients who needed to see their GP. No formal evaluation of CPs' views towards the scheme was conducted.

A critical element in the success of any pilot service run in pharmacies is to explore the views of stakeholders, with CPs being a key group. It is vital to determine barriers and facilitators early in the process to inform not only wider implementation of the service but also the next stages of the pilot, using an iterative approach. The aim of this study was therefore to explore the views and opinions of CPs regarding their initial experience of and levels of preparedness for the new STTT service in Wales.

\section{Methodology}

The first cycle of an action research project was employed, and a phenomenological qualitative approach was adopted with a constructivist research paradigm, using semi-structured interviews. Potential participants were identified through purposive sampling, via NHS Wales Informatics Service (NWIS) who held details on the participating pharmacies and consultations conducted. The sampling frame included all 34 trained pharmacists in the 23 participating pilot sites. These were established premises which had been providing CAS for a minimum of 6 months and employed pharmacists with a work pattern that could ensure continuity of service provision. Pharmacists in those pharmacy branches were familiar with Choose Pharmacy, the national information technology (IT) tool that is being used for the provision of pharmacy services, including CAS and STTT.

An invitation email, information sheet and consent form were distributed to all accredited pharmacists via the clinical lead for the service, with an aim to recruit CPs who had completed at least three consultations within the first 3 weeks of the service, so results could be fed back to the implementation team for any urgent actions required. Pharmacists were asked to contact the researcher directly once they had completed the required number of consultations. All pharmacists who contacted the researcher and provided written consent participated. Interviews were delayed where possible to allow the pharmacists to gain more experience with conducting the service. The topic guide for the interviews included sections on reasons for participating in the pilot, experiences with setting up the service, collaboration with GPs, confidence levels before and after the training, patient attitudes towards the service overall and towards service outcomes in particular, and overall flow of workload during and following a consultation. Interviews were audio recorded with written consent, and transcribed ad verbatim; complete anonymisation was ensured at the transcribing phase. The anonymised transcripts were coded independently by two researchers in MS Word 2016 and codes thematically analysed in order to identify common themes emerging from the data, using an inductive approach. ${ }^{8}$ Any differences in coding were discussed and a consensus was reached. A third researcher reviewed the coding and emerging themes. The researchers were all registered or trainee pharmacists and, as such, a reflexive approach was adopted. ${ }^{9}$ The study received ethical approval from the Cardiff School of Pharmacy and Pharmaceutical Sciences Research Ethics Committee.

The SRQR checklist for qualitative studies was utilised to guide the reporting of this study and is included as Supplementary Table 1.

\section{Results}

Twelve pharmacists fit the inclusion criteria and were eligible for interviews. A total of seven face-to-face interviews were conducted within the data collection period (19th November12th December). Five out of the seven pharmacists interviewed were working as single pharmacists in their branch. Participant characteristics are presented in Supplementary Table 2. Three main themes and subthemes emerged from the analysis (Figure 2); Table 1 presents representative quotes from each.

\section{Theme I: Impact On Patient Care}

CPs discussed how the structure of the service and technology infrastructure were crucial in ensuring the service's success, the perceived role of the service towards contributing to antimicrobial stewardship, and how it was believed that STTT would rebalance primary care resources so that workload is distributed appropriately amongst healthcare professionals.

\section{Service Set-Up As A Tool For Patient Education}

The structure of the service within the IT application was considered very supportive, guiding pharmacists through the consultation, making sure they ask all the necessary questions. The IT application itself, Choose Pharmacy, was perceived by all participants as essential, allowing them access to patient information, despite occasional issues with logging in reported by two of the pharmacists. It was recognised that Choose Pharmacy was in the process 


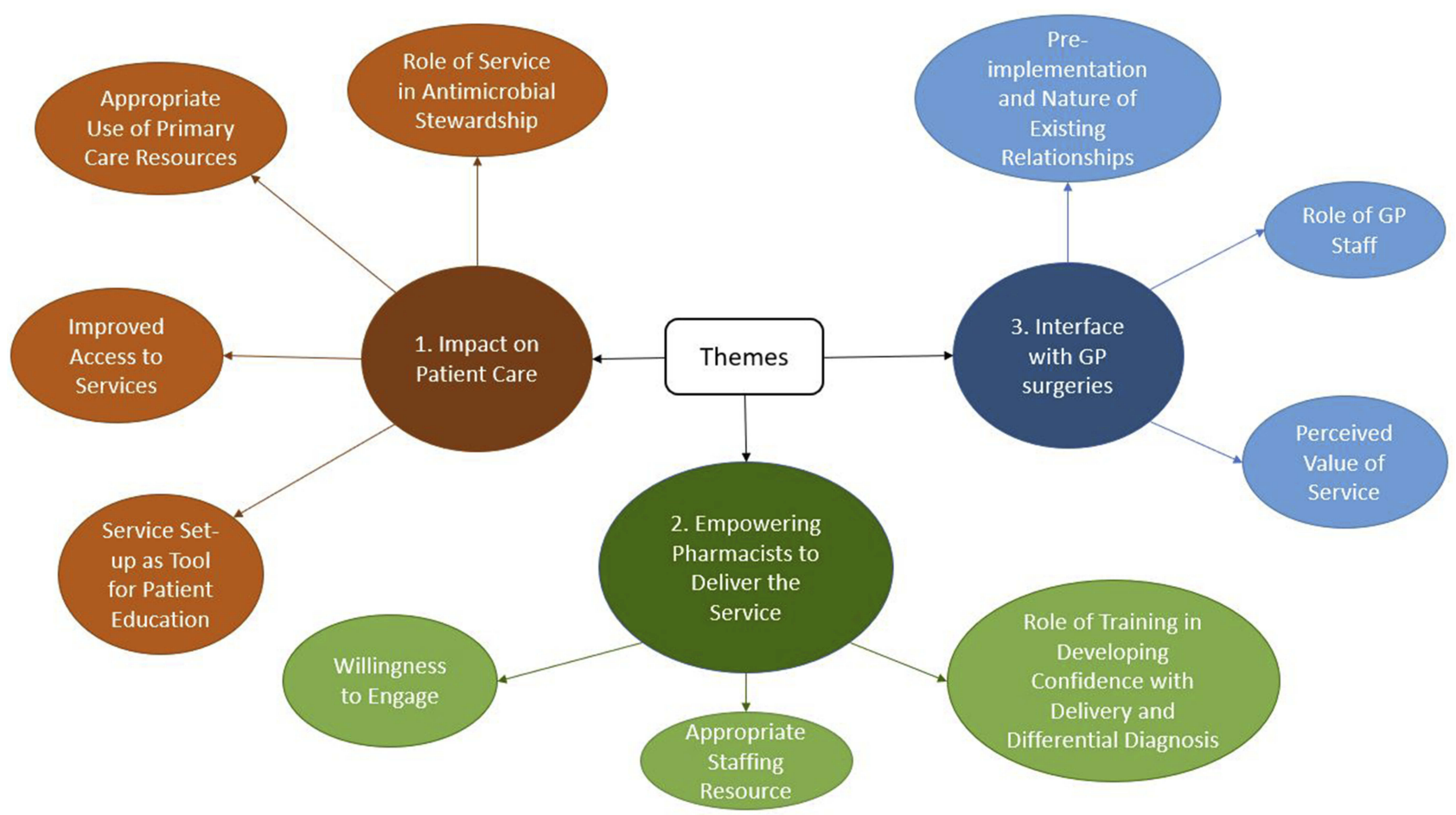

Figure 2 A schematic representation of the main themes and subthemes emerging from inductive thematic analysis of interviews with 7 pharmacists, in relation to providing the pilot Sore Throat Test and Treat (STTT) service in Wales.

of developing further and would eventually provide access to patient GP records, essential for the future:

Participant (PA) 6: It [Choose Pharmacy] does [act like a guide], certainly with the sore throat test and treat, it pretty much will lead you through the order you need to go in on the consultation, so it's really innovative it that way.

PA4: It [Choose Pharmacy] gives us access to patient information, eventually access to some of the care records of the patient for more effective and safer treatment."

All participants believed the POCT result was a vital aspect when making their decision on treatment for the patient. One participant suggested without the POCT, pharmacists would prescribe unnecessary antibiotics, which would have adversely impact on the fight against AMR.

Having the POCT result also supported patient education, as it was considered an evidential tool on which to base discussions around the outcome of the consultation. All participants reported that sharing the POCT result made patients more accepting of the consultation outcome, regardless of whether an antibiotic was supplied:

PA3: ... so I think actually having that physical evidence in front of you, not only does it make you feel more confident in your diagnosis and your decision, but also you've got it there to fall back

\section{Role Of Service In Antimicrobial Stewardship}

Five participants discussed how the service gave them the opportunity to educate patients on the difference between the self-limiting nature of viral infections and bacterial infections which may, in some cases, require antibiotics. Participants believed STTT would not only reduce the number of antibiotics supplied as a result of current consultations, but it would educate patients to not always expect antibiotics in the future, thus changing behaviour. This was an opportunity for pharmacists to implement antimicrobial stewardship, which could potentially contribute positively to the fight against AMR:

PA1: I think it's such a valued one [STTT], and we talk about antibiotic resistance and things like that, which is huge all right. You know, the facts that we were shown on the day of the training you know, and how certain countries have got it so missed managed, it's got to be done.

\section{Appropriate Use Of Primary Care Resources}

All but one participant discussed that implementing STTT could potentially reduce the number of GP appointments for uncomplicated sore throats. At the same time patients were educated about the role of the pharmacist and appropriate use of NHS resources and choice of healthcare professional beyond sore throats, by increasing confidence in consulting with pharmacists for other conditions: 
Table I Representative Quotes From The Main Themes And Subthemes Emerging From Inductive Thematic Analysis Of Interviews With 7 Pharmacists, In Relation To Providing The Pilot Sore Throat Test And Treat (STTT) Service In Wales

\begin{tabular}{|c|c|}
\hline \multicolumn{2}{|c|}{ Theme I: Impact on Patient Care } \\
\hline $\begin{array}{l}\text { Service set-up as a } \\
\text { tool for patient } \\
\text { education }\end{array}$ & $\begin{array}{l}\text { PA3: “... so I think actually having that physical evidence in front of you, not only does it make you feel more confident in your diagnosis and your } \\
\text { decision, but also you've got it there to fall back" } \\
\text { PA6: "It [Choose Pharmacy] does [act like a guide], certainly with the sore throat test and treat, it pretty much will lead you through the order } \\
\text { you need to go in on the consultation, so it's really innovative it that way." } \\
\text { PA4: "It [Choose Pharmacy] gives us access to patient information, eventually access to some of the care records of the patient for more } \\
\text { effective and safer treatment." } \\
\text { PA4: "It's [Choose Pharmacy] in its infancy, it's developing as time goes on, but it has to be the way forward hasn't it." }\end{array}$ \\
\hline $\begin{array}{l}\text { Role of service in } \\
\text { antimicrobial } \\
\text { stewardship }\end{array}$ & $\begin{array}{l}\text { PA3: "... I mean antibiotic stewardship with this service I think is fab, especially because sore throat is such a common reason why } \\
\text { people go to their GP." } \\
\text { PAI: "I think it's such a valued one [STTT], and we talk about antibiotic resistance and things like that, which is huge all right. You } \\
\text { know, the facts that we were shown on the day of the training you know, and how certain countries have got it so missed managed, } \\
\text { it's got to be done." }\end{array}$ \\
\hline $\begin{array}{l}\text { Appropriate use of } \\
\text { primary care } \\
\text { resources }\end{array}$ & $\begin{array}{l}\text { PA6: "I think it [STTT] would be really positive for pharmacy. For us to show that we can actually make an impact on patient care } \\
\text { and for GPs, it [STTT] should reduce their workload a lot, because I'm sure they see an awful lot of people with sore throats that } \\
\text { could be dealt with by this service." } \\
\text { PA4: "Yes, we can reduce the workload of the GP, but it's also about educating our patients and reassuring our patients they don't } \\
\text { need to see a GP." }\end{array}$ \\
\hline $\begin{array}{l}\text { Improved access to } \\
\text { services }\end{array}$ & $\begin{array}{l}\text { PA5: "... it's really good that we can like offer extra services to the customers who come to us for advice anyway about over the } \\
\text { counter stuff like sore throat, so it's really good to have an add on and just provide them with a bit more of a better service ... } \\
\text { PA6: "Um ye they seemed to be um they find it easier than, a lot of the time with the surgery next door particularly they'll have to } \\
\text { wait a number of days, sometimes weeks for an appointment anyway so they're quite happy that they can just come in and be seen" }\end{array}$ \\
\hline \multicolumn{2}{|c|}{ Theme 2: Empowering Pharmacists to Deliver the Service } \\
\hline $\begin{array}{l}\text { Role of training in } \\
\text { developing } \\
\text { confidence with } \\
\text { delivery and } \\
\text { differential diagnosis }\end{array}$ & 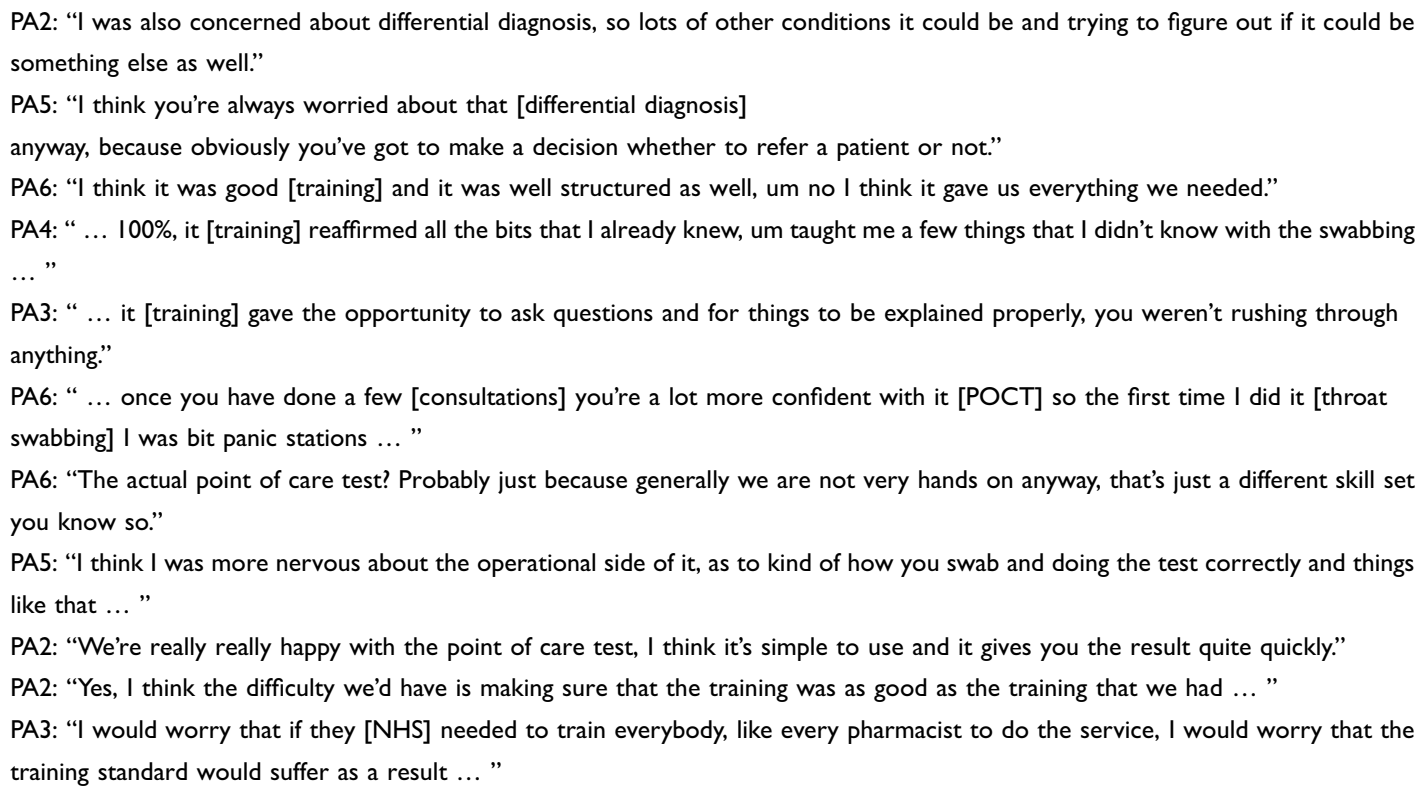 \\
\hline $\begin{array}{l}\text { Appropriate staffing } \\
\text { resource }\end{array}$ & $\begin{array}{l}\text { PA2: "I had concerns about how long it was going to take, to run the actual test. We were told, a bit vague about } 5 \text { to } 10 \text { mins" PA3: "I } \\
\text { think because we're two pharmacists no [New service effect workflow]. But I think if you were a pharmacist on your own then I think } \\
\text { it could, quite badly really [New service effect workflow]." } \\
\text { PA6: "It does um, but it's the same as any service really in community pharmacy, if you're doing a service with a patient, unless youhave } \\
\text { got a second pharmacist, you're not going to be there for the walkJins and things. So, you might come out of a consultation and find } \\
\text { you've got a load of people waiting in the shop." }\end{array}$ \\
\hline
\end{tabular}


Table I (Continued).

\begin{tabular}{|c|c|}
\hline $\begin{array}{l}\text { Willingness to } \\
\text { engage }\end{array}$ & $\begin{array}{l}\text { PA4: "Because you have to understand that not all pharmacists are at the stage of their career where they want to be developing new } \\
\text { skills. Lots might be at the stage of their career where the think you know, sort of like rolling it down a bit now and just taking } \\
\text { a bit of a back step." } \\
\text { PA6: "Um because I know of, I know there are plenty of pharmacists around who still don't do MURs or don't engage in DMRs and things, so } \\
\text { those sorts of pharmacists are unlikely then to engage with this sort of service you know." } \\
\text { PA6: "Yep, I think so. But maybe what you'd have to do is look at the people who are already engaged with other areas of choose pharmacy first } \\
\text { and prioritise them and then you work on engagement with the people who aren't currently providing other choose pharmacy services." }\end{array}$ \\
\hline \multicolumn{2}{|c|}{ Theme 3: Interface with GP surgeries } \\
\hline $\begin{array}{l}\text { Pre-implementation } \\
\text { and nature of } \\
\text { existing } \\
\text { relationships }\end{array}$ & $\begin{array}{l}\text { PA4: "... I get to talk to most of the GPs on a weekly basis, not every day but the relationship is good ..." } \\
\text { PA2: "No, we've got good relationships with the GPs here, so we see them every day ..." } \\
\text { PA5: "It is always difficult to get in contact with the GPs because they are so busy, um so the way we actually did was I just kind of } \\
\text { went over there, kind of dropped in on them, didn't actually get to speak to the GPs because it's quite hard to get to speak to them so } \\
\text { I just spoke to the receptionist staff about it ..." }\end{array}$ \\
\hline $\begin{array}{l}\text { Perceived value of } \\
\text { service }\end{array}$ & $\begin{array}{l}\text { PA7: “ ... but it wasn't so much that but yes they [GPs] were really really receptive of it [STTT] as well, and they [GPs] seem quite } \\
\text { excited about it." } \\
\text { PA3: “... and in that cluster we [Pharmacist and GPs] discussed a few different things, one of which was sore throat test and treat and } \\
\text { all the GP's were really really keen for the service ..." " } \\
\text { PA6: "So that was fairly easy [contacting GPs]. There's been a bit of feedback from the surgeries that, they've sort of said well why } \\
\text { can't we have the same equipment to do the same tests." }\end{array}$ \\
\hline Role of GP staff & $\begin{array}{l}\text { PA4: “... so as well as having to speak to the GPs, it's not as much the GPs, it's the receptionist and the practice manager, because } \\
\text { they are the people who are answering the phone to that initial request for the service." } \\
\text { PA7: "They [receptionists] seem to really like it [STTT] actually because I think it takes a lot of pressure of them to send anyone with } \\
\text { a sore throat up here, rather than to find a space for an appointment for them." } \\
\text { PA2: " ... so they're [GPs] really chuffed with this and the staff on the counter are really chuffed as well because there is less pressure } \\
\text { to fill GP appointments and they're already struggling with them to be honest." }\end{array}$ \\
\hline
\end{tabular}

PA4: Yes, we can reduce the workload of the GP, but it's also about educating our patients and reassuring our patients they don't need to see a GP.

\section{Improved Access To Services}

Six participants believed that the main benefit of the service was increasing public choice and accessibility. It was felt that provision of only symptomatic relief for sore throat under CAS limited CPs' role, preventing them from providing the best care to their patients:

PA5: ... it's really good that we can like offer extra services to the customers who come to us for advice anyway about over the counter stuff like sore throat, so it's really good to have an add on and just provide them with a bit more of a better service ...

\section{Theme 2: Empowering Pharmacists To Deliver The Service}

A number of factors were highlighted in relation to ensuring pharmacists were ready and willing to provide the STTT service.

\section{Role Of Training In Developing Confidence With Delivery And Differential Diagnosis}

A number of concerns were reported, in particular around the decision-making process for differential diagnosis and when there was a need to refer a patient to another healthcare professional. Three participants reported their concern about using the POCT and completing a throat swab, as it was a new skill for them:

PA2: I was also concerned about differential diagnosis, so lots of other conditions it could be and trying to figure out if it could be something else as well.

PA5: I think I was more nervous about the operational side of it, as to kind of how you swab and doing the test correctly and things like that ...

All participants stated that the training addressed these concerns, meeting their needs and expectations. They stated the training day was structured well, provided the opportunity to become familiar with the POCT kit, and included everything needed to be able to carry out the service competently. Some participants already felt confident before the training but 
believed the information provided reinforced their knowledge. Two pharmacists stated that they were not entirely confident until they gained experience having completed a few consultations in practice. Participants firmly believed that the quality of training should be maintained, regardless of the resource implication for national roll-out:

PA4: ... $100 \%$, it [training] reaffirmed all the bits that I already knew, um taught me a few things that I didn't know with the swabbing ...

PA2: Yes, I think the difficulty we'd have is making sure that the training was as good as the training that we had ...

\section{Appropriate Staffing Resource}

Five participants were concerned with how long consultations would take and the impact of this on the workflow in the pharmacy, especially when a second pharmacist was not present. Some cases were noted whereby time constraints meant that follow-up phone calls with patients (a part of the service evaluation) could not be completed. Four participants expressed their growing concern regarding increasing pharmacists' workload as they offer an increasing range of additional services. It was highlighted that the rebalance of services within primary care needs to be accompanied by appropriate consideration to staffing resources within the pharmacy.

PA6: ... if you're doing a service with a patient, unless you have got a second pharmacist, you're not going to be there for the walk-ins and things. So, you might come out of a consultation and find you've got a load of people waiting in the shop.

\section{Willingness To Engage}

All participants were very enthusiastic about providing STTT and believed this willingness is key for any scheme's success. It was discussed that some pharmacists may not be as keen to develop their role further and provide additional services, which could potentially pose a problem in a future national roll-out of the STTT service.

PA4: Because you have to understand that not all pharmacists are at the stage of their career where they want to be developing new skills. Lots might be at the stage of their career where the think you know, sort of like rolling it down a bit now and just taking a bit of a back step.

\section{Theme 3: Interface With GP Surgeries}

Participants discussed the attitudes of GPs and GP staff towards pharmacy and STTT.

\section{Pre-Implementation And Nature Of Existing Relationships}

All except one participant reported having a good relationship with local GPs, which enabled successful communication of the service objectives prior to implementing the service. It was believed that good relationships with local GPs support the success of the services pharmacists offer, as GPs then feel confident in referring patients to the pharmacy. One pharmacist noted the lack of positive pre-existing relationships with the GPs that led to communicating information related to STTT to the receptionists instead.

PA5: It is always difficult to get in contact with the GPs because they are so busy, um so the way we actually did was I just kind of went over there, kind of dropped in on them, didn't actually get to speak to the GPs because it's quite hard to get to speak to them so I just spoke to the receptionist staff about it ...

\section{Perceived Value Of Service}

Participants who discussed the STTT service with GPs received very positive feedback. GPs appeared to be enthusiastic about the introduction of the service as it could potentially reduce their workload in relation to acute sore throats. One participant reported having a query from a GP in relation to the POCT kit enquiring whether it could be made available to GPs.

PA7: ... but it wasn't so much that but yes they [GPs] were really really receptive of it [STTT] as well, and they [GPs] seem quite excited about it.

\section{Role Of GP Staff}

Participants highlighted the key role of GP staff in ensuring the service's success, as they would be at the frontline making referrals, by taking phone calls and signposting patients to local pharmacies. Informal conversations between pharmacists and receptionists revealed that GP staff were enthusiastic about the new service, as they believed it would relieve pressure for them having to find appointments for patients.

PA4: ... so as well as having to speak to the GPs, it's not as much the GPs, it's the receptionist and the practice manager, because they are the people who are answering the phone to that initial request for the service.

\section{Discussion}

This study aimed to explore the views and opinions of community pharmacists who provided at least three 
consultations during the first three weeks of the pathfinder STTT service, in relation to their initial experiences and preparedness for the service. To the authors' knowledge, this is the first study that obtained pharmacists' feedback to providing a Sore Throat Test and Treat service internationally. Overall, results indicate that pharmacists are ready and willing to provide the service and that STTT may fit in well with the Welsh Government's AMR Delivery Plan. ${ }^{10}$ Minor technical difficulties with logging in to the IT platform were identified and communicated to NWIS. No other issue was identified that required urgent action.

Data from the interviews conducted suggest that the use of point-of-care testing and the STTT service structure is guiding pharmacists to supply antibiotics more appropriately. This is in line with literature that has shown how POCT in areas of practice other than sore throats is supporting healthcare professionals to reduce the number of antibiotics prescribed, which in turn contributes to the fight against AMR. ${ }^{11-13}$ No concerns were raised about patient attitudes towards provision of the service by a pharmacist instead of a GP or towards a negative POCT result and the subsequent decision not to supply an antibiotic. It was perceived that patients were still satisfied with the consultation itself as well as the outcome, supporting the findings of Courtenay et al. ${ }^{14}$ who discussed patient satisfaction with antibiotic-related supply from non-medical prescribers and of literature recognising the value of pharmacists in the global fight against AMR. ${ }^{15}$

Participants in the study recognised the increasing pressures on GPs that have been reported elsewhere in the literature ${ }^{16,17}$ and acknowledged that services such as the STTT could not only rebalance GPs' workload but also improve patient access to healthcare. To ensure the success of this transition, data from the study suggest that communication and collaborative working between community pharmacists and GPs are vital, in line with recommendations of the British Medical Association report. ${ }^{18}$ Quality and consistency of training have also been highlighted as crucial factors to the successful implementation of the new service and past reports have recognised how insufficient or lack of training received by healthcare professions can lead to negative patient outcomes. ${ }^{19,20}$

Other work evaluating the STTT service will include exploring patient, GP and GP practice staff's views and experiences of the service, an economic evaluation, and changes in the pattern of use as the service becomes normalised. Results from the first few months of the service indicate high patient satisfaction and a small overall reduction in supply of antibiotics with no associated unintended harm arising for the patients. ${ }^{21}$

The short data collection period meant that it was not possible to confirm that theoretical saturation had been reached, and the sampling frame was limited to twelve pharmacists only. It was not anticipated that results from this study would be generalisable, as this was the first cycle in action research aiming to obtain initial pharmacist views. The themes from the current analysis will inform the development of a questionnaire that will explore a larger and more representative sample size of pharmacists' experiences and continuing development needs after providing the service for 12 months.

\section{Conclusion}

The new STTT service has been well received by pharmacists who recognised the service's role in providing patient education and contributing to principles of antimicrobial stewardship and described factors that would empower them to deliver the service confidently. Results may be of interest to policy makers internationally, as the use of community pharmacies in the treatment of uncomplicated sore throat is important in reducing pressure on primary care services and providing care for population less able to access their GP whilst prevention of more serious complications may be beneficial to antimicrobial stewardship.

\section{Disclosure}

The authors report no conflicts of interest in this work.

\section{References}

1. Fletcher-Lartey S, Yee M, Gaarslev C, Khan R. Why do general practitioners prescribe antibiotics for upper respiratory tract infections to meet patient expectations: a mixed methods study. BMJ Open. 2016;6:e12244. doi:10.1136/bmjopen-2016-012244

2. Welsh Government. Prescriptions dispensed in the community: 2016. 2017. Available from: https://gov.wales/prescriptions-dispensed-com munity-2016. Accessed November 20, 2018.

3. All Wales Medicines Strategy Group. All Wales common ailments service formulary. 2018. Available from: http://www.awmsg.org/docs/ awmsg/medman/A11\%20Wales\%20 Common\%20Ailments\% 20Formulary.pdf. Accessed October 25, 2018.

4. National Institute for Health and Care Excellence. Point-of-care diagnostic testing in primary care for strep A infection in sore throat. 2018. Available from: https://www.nice.org.uk/advice/mib145/resources/poin tofcare-diagnostic-testing-in-primary-care-for-strep-a-infection-insore-throat-pdf-2285963457844165. Accessed November 3, 2018.

5. Buss V, Deeks L, Shield A, Kosari S, Naunton M. Analytical quality and effectiveness of point-of-care testing in community pharmacies: a systematic literature review. Res Social Adm Pharm. 2019;15:483495. doi:10.1016/j.sapharm.2018.07.013

6. Williams E. Personal Communication with Service Clinical Lead. Sore Throat Test and Treat Service Specification. Wales: NHS Wales Informatics Service; 2018. 
7. Thornley T, Marshall G, Howard P, Wilson A. A feasibility service evaluation of screening and treatment of group A streptococcal pharyngitis in community pharmacies. $J$ Antimicrob Chemother. 2016;71:3293-3299. doi:10.1093/jac/dkw264

8. Braun V, Clarke V. Using thematic analysis in psychology. Qual Res Psychol. 2006;3(2):77-101. doi:10.1191/1478088706qp063oa

9. Dodgson J. Reflexivity in qualitative research. J Hum Lact. 2019;35 (2):220-222. doi:10.1177/0890334419830990

10. Welsh Government. Together for health tackling antimicrobial resistance and improving antibiotic prescribing. 2016. Available from: http://www.wales.nhs.uk/sitesplus/documents/888/Antimicrobial\% 20Resistance\%20Delivery\%20Plan.pdf. Accessed November 10, 2018.

11. Aabenhus R, Jensen JS, Jørgensen K, Hróbjartsson A, Bjerrum L. Use of rapid point of care testing for infection to guide doctors prescribing antibiotics for acute respiratory infections in primary care settings. Cochrane Database Syst Rev. 2014;11:CD010130. Available from: https:/www.cochrane.org/CD010130/ARI_use-ofrapid-point-of-care-testing-for-infection-to-guide-doctors-prescrib ing-antibiotics-for-acute-respiratory-infections-in-primary-care-set tings. Accessed August 28, 2019.

12. Cooke J, Butler C, Hopstaken R, et al. Narrative review of primary care point of care testing (POCT) and antibacterial use in respiratory tract infection (RTI). BMJ Open Respir Res. 2015;2:e000086. doi:10.1136/bmjresp-2015-000086

13. Minnaard MC, Van de Pol AC, Hopstaken $\mathrm{R}$, et al. C reactive protein point of care testing and associated antibiotic prescribing. Fam Pract. 2016;33(4):408-413. doi:10.1093/fampra/cmw039

14. Courtenay M, Rowbotham S, Lim R, et al. Antibiotics for acute respiratory tract infections: a mixed methods study of patient experiences of non-medical prescriber management. BMJ Open. 2017;7: e013515. doi:10.1136/bmjopen-2016-013515
15. Jones LF, Owens R, Sallis A, et al. Qualitative study using interviews and focus groups to explore the current and potential for antimicrobial stewardship in community pharmacy informed by the Theoretical Domains Framework. BMJ Open. 2018;8:e025101. doi:10.1136/ bmjopen-2018-025101

16. Thompson M, Walter F. Increases in general practice workload in England. Lancet. 2016;387:2270-2272. doi:10.1016/S0140-6736(16) 00743-1

17. Fisher RFR, Croxson CHD, Ashdown HF, Hobbs FDR. GP views on strategies to cope with increasing workload: a qualitative interview study. Br J Gen Pract. 2017;67(655):148-156. doi:10.3399/bjgp17X688861

18. British Medical Association (BMA). Improving communication between community pharmacy and general practice. 2009. Available from: http://www.bma.org.uk/-/media/Files/PDFs/Practical \%20advice\%20at\%20work/Doctors\%20as\%20managers/gppharmim provingcommunicationworkbook.pdf. Accessed January 5, 2019.

19. Francis R Report of the Mid Staffordshire NHS Foundation Trust public inquiry executive summary. 2013. Available from: https:// assets.publishing.service.gov.uk/government/uploads/system/uploads/ attachment_data/file/279124/0947.pdf. Accessed January 9, 2019.

20. Andrews J, Butler M. The Andrews Report "Trusted to Care" An independent Review of the Princess of Wales Hospital and Neath Port Talbot Hospital at ABMU Health Board. 2014. Available from: http:// www.wales.nhs.uk/sitesplus/documents/863/Trusted $\% 20$ to $\% 2 \overline{20 \text { Care }}$ \%20-\%20An\%20Independent $\% 20$ Review\%20of $\% 20$ the $\% 20$ Princess $\% 20$ of $\% 20$ Wales $\% 20$ Hospital $\% 20$ and $\% 20$ Neath $\% 20$ Port $\% 20$ Talbot \%20Hospitals\%20at\%20ABMU.pdf. Accessed January 9, 2019.

21. Mantzourani E. Evaluating the first NHS funded sore throat test and treat service in the UK. Pharm J. 2019. Available from: https://www. pharmaceutical-journal.com/20206884.article?utm_campaign=2488 Clinical_Pharmacist\&utm_medium $=$ email\&utm_source $=$ Pharmaceutical\%20Journal. Accessed September 5, 2019.
Integrated Pharmacy Research and Practice

\section{Publish your work in this journal}

Integrated Pharmacy Research and Practice is an international, peerreviewed, open access, online journal, publishing original research, reports, reviews and commentaries on all areas of academic and professional pharmacy practice. This journal aims to represent the academic output of pharmacists and pharmacy practice with particular focus on integrated care. All papers are carefully peer reviewed to ensure the highest standards as well as ensuring that we are informing and stimulating pharmaceutical professionals. The manuscript management system is completely online and includes a very quick and fair peer-review system, which is all easy to use. Visit http://www.dovepress.com/testimonials.php to read real quotes from published authors. 